\title{
Lisa Nagel
}

\section{The Picturebook App as Event Interactivity and Immersion in Wuwu \& Co}

\begin{abstract}
This article explores analytical perspectives from theatre studies as an approach to analysing interactivity in picturebook apps, using the critically acclaimed Danish picturebook app Wuwu \& Co. - A Magical Picturebook (2014) by Merete Pryds Helle and Kamila Slocinska as a case study. Drawing on theatre scholar Willmar Sauter's analytical concept the theatrical event, the article proposes that interactive digital narratives for children should be analysed as events, as interactivity takes place between a reader and the work. To discuss the interactive features of the app, the article applies literature scholar Marie-Laure Ryan's theories of narrative as virtual reality, especially with regards to the relationship between interactivity and immersion. In the analysis, the interactive features are examined with regards to both how the reader is allowed to participate as co-creator of the narrative as well as how the interactivity is experienced. The analysis shows what can be described as a discrepancy between the interactive and immersive experiences offered, caused by the interactive features that at different moments interrupt either temporal, spatial or emotional immersion. This happens even though the interactivity with Ryan's terms can be described as internal-ontological, and thus as related to the narrative. As a consequence, a discussion of the significance of interactivity in digital narratives for children cannot be limited to including the formal, intra-fictional relationship between the narrative and the interactive features. Rather, it must also include the reader and the reading experience. This means that an analysis of interactivity in digital narratives on tablets will have to include both a discussion of how the interactive features are intended to work, and further, an evaluation of the actual effect of the interactive features, when realised by a reader in a live event.
\end{abstract}

Keywords: picturebook apps, digital narratives for children, reading as an event, immersion, theatrical event, reader as co-creator, Wuwu $\mathcal{E}$ Co. - A Magical picturebook, Merete Pryds Helle, Kamila Slocinska 
With the emergence of digital narratives for children, published as apps for tablet computers, interactivity has become a central feature in children's literature. Whereas picturebooks printed on paper invite the reader to interact physically with the story by for instance turning the page, opening flaps or pressing buttons, the readers of digital narratives are invited to interact by touching, shaking, blowing, shouting, dancing and filming as part of the experience, to name a few examples. This increased opportunity for the child reader to participate, co-create and interact leaves the children's literature researcher with the challenge of identifying the aesthetic implications of interactivity, and it more than suggests that a thorough discussion of interactivity is called for.

An important topic in research on digital narratives for children is the aesthetic value of interactivity. Within the body of research that focuses on textual analysis, this value seems to co-relate with the degree to which the reader is allowed to influence the narrative in different ways, and also with how and whether or not the features can be understood as contributing to the meaning making process (Turrión; Stichnothe; Schwebs; Al-Yaqout and Nikolajeva). Celia Turrión, for example, distinguishes between true, false and simulated interactivity, false being synonymous with "cases where the effect of the user's actions is repetitive or meaningless for the development of the story" (4). Ghada Al-Yaqout and Maria Nikolajeva similarly suggest that an "increasing degree of interactivity leads into imaginative co-creation rather than merely making things jump, squeak, or shake on a screen" (4). What these examples show is that whereas some interactive features are regarded as enhancing the narrative and thus as valuable, other features are perceived as not contributing to the narrative, and consequently as unnecessary and superficial.

Such an approach to interactivity is problematic in the sense that it leaves the reader and the reading experience out of the equation. Interactivity requires the participation of the reader to take place, and is not only experienced cognitively as part of a narrative, but also emotionally and physically, as an embodied experience. For this reason, the significance of interactivity cannot be discussed without taking into consideration how the interactive features affect the reader, which suggests that a thorough examination of interactivity requires a thorough examination of the reading experience as well.

As a consequence, this article explores analytical perspectives from theatre studies as an approach to analysing interactivity in picturebook apps. In order to activate this perspective, I analyse the critically acclaimed Danish app Wuwu \& Co. - A Magical Picturebook 
(2014) by Merete Pryds Helle (text) and Kamila Slocinska (visual concept). Other contributors are Aksel Køie (producer), Tim Garbos (interaction design), André Taono (programmer and technical artist), Jesper Ankarfeldt (music and sound) and Alistair Findlay (English narrator). The app combines a literary narrative and interactive features in a way that requires the reader to become a co-creator of the narrative in a variety of ways. In my analysis, I examine these features with regards to both how the reader is allowed to participate in creating the narrative as well as how the interactivity is experienced. By analysing the app as an event, I hope to shed light on the need for an updated analytical perspective on picturebook apps in general, as well as on how the aesthetic significance of interactivity is related to the reading experience as well as the narrative structure.

\section{Methodological Approach}

To regard picturebook apps as events is an analytical approach that draws on theoretical perspectives from theatre studies, specifically that of theatre scholar Willmar Sauter who argues that theatre should be regarded as an event taking place in time and space, rather than an autonomous work of art. Sauter substantiates this concept by arguing that theatre is a phenomenon that does not exist as a physical reality unless it is an event including both performer and spectator (6). A theatrical event, according to Sauter, "always takes place at a certain place, at a certain time, and in a certain context," and furthermore, "presupposes two partners: those who make a presentation and those who perceive it" (30).

A similar perspective to that of Sauter can be found in the writings of literary scholar Louise M. Rosenblatt, who in several seminal works have argued that reading should be regarded as an event, giving the reader the role of the creator of the work of art ("The Poem as Event"; The Reader, the Text, the Poem). Rosenblatt distinguishes between the text, which is the literary text, and the poem, which is the name she gives the story that the reader brings to life during the reading of the text. However, whereas the event Rosenblatt describes takes place in the mind of the reader, and relates to the meaning making process of reading, Sauter's concept of the theatrical event exceeds the imagination of the reader, and incorporates the real life event in a specific and societal context (Sauter 34). Worth mentioning is also literary scholar N. Katherine Hayles, who argues that electronic poetry can be understood as events, because of how time forms part of the artistic expression. 
Although far from being a theatrical performance, it is possible to argue that an app also can be analysed as an event within the frames of this concept. The relationship between an app and its reader is even more explicit than that of a theatre performance and its audience, as the app requires physical interference from the reader to take place at all. The reading of an app also takes place at a certain place, at a certain time, and in a certain context, but in contrast to a theatrical performance, there is no performer. Rather, there is an app presenting a narrative, and the reader has to simultaneously execute and perceive the narrative. This does not challenge the concept of an app as an event, but rather, accentuates the importance of the reader in picturebook apps. It also means that the reading of an app becomes an important part of an analysis.

To analyse a picturebook app as an event means placing the reading of the app in the centre of the analysis alongside the app itself. As a researcher, one can therefore no longer regard the app from outside, separate from oneself. Rather, the experience of the researcher forms part of the object of investigation. This suggests a phenomenological approach that takes into consideration the physiological, emotional and cognitive experiences of reading the interactive features of the app as object of study, as well as the features themselves. My understanding of reading experience also relates to the hermeneutic process of experiencing art as defined by German philosopher Hans-Georg Gadamer. Gadamer describes the experience of art as closely related to the experience of play, and play as a phenomenon that exists in between the work of art and the spectator (103).

In the article, I focus on how the app can be experienced when realised by a reader, and not only on the formal characteristics of the app. The fact that the app is created for children might present itself as a challenge in this regard. However, my aim is not to decide whether the interactive features in the app are valuable for children or not, but to shed light on how the structuring of the interactive features relates not only to the narrative, but also to the reader. I do not argue that my analysis is representative for all experiences, but rather propose that analysing apps as events makes visible certain aspects of a work, as exemplified in the analysis of Wuwu $\mathcal{E}$ Co.

\section{Theoretical Framework: Narrative as Virtual Reality}

As interactivity can be understood as something that takes place between the reader and the narrative, the discussion of how it is experienced requires a theoretical perspective that incorporates both these 
entities. Such a perspective is offered by media and literature scholar Marie-Laure Ryan, who proposes the concept of virtual reality (VR) as a means of describing the types of reader response that may be elicited by a literary text of either the print or the electronic variety. Looking to Pimentel and Teixeira, Ryan defines VR as an interactive, immersive experience generated by a computer (2). She then uses the concept of VR as a starting point, and singling out and transferring the two concepts of immersion and interactivity from the technological to the literary domain, develops them into the cornerstones of a phenomenology of reading and experiencing art.

The relations between interactivity and immersion can be understood through the lens of what Ryan, with reference to Aylett and Louchart, refers to as the paradox of interactivity, meaning the conflicting interests between the author's control over the narrative and the reader's autonomy as a co-creator of the narrative (12). Co-creation is, however, not limited to influencing the narrative, but also includes the ways in which the reader can relate to it through immersion. To Ryan, immersion is not just any pleasurable artistic experience, but an experience that presupposes an imaginative relationship to a world projected by a text (3). She states: "In the phenomenology of reading, immersion is the experience through which a fictional world acquires the presence of an autonomous, language-independent reality populated by live human beings" (9). Plot is therefore not a requirement, only the creation of a space to which the reader can relate and that is the setting for a potential narrative action. Ryan suggests three types of immersion - spatial, temporal and emotional - as a way to approach an analysis of immersion in a narrative (10). She relates spatial immersion to the creation of a sense of space and atmosphere, temporal immersion to the experience of the story and the passing of time, whilst emotional immersion deals with the character and how the literary work affects the reader (86).

What Ryan calls the aesthetics of interactivity, on the other hand, presents the text as a game, language as plaything and the reader as the player (10). In trying to lay down the foundations of a theory of interactivity, she suggests that interactivity can be analysed according to several criteria, in what she calls a taxonomy based on the cross-classification of two dichotomies: internal versus external interactivity and exploratory versus ontological interactivity (162). The first pair classifies the relation of the user to the textual world. Interactivity is internal when the reader of an interactive text plays the role of an individuated member of the storyworld, and external when the reader does not imagine herself as a member of the story- 
world or when she controls the storyworld from a godlike perspective. Interactivity is exploratory when the involvement with the storyworld has no lasting consequences, and ontological when the reader's actions cause events that bring lasting changes (162).

Moving on, I examine the paradox of interactivity in Wuwu $\mathcal{E}$ Co. using Ryan's concept of VR as lens. Analysing the app as an event, and interactivity as something taking place between the reader and the app, I focus on both the creation of a world and on the sensations of games, and see how I experience these dimensions as a reader. The question guiding my analysis is: What is the relationship between interactivity and immersion in the app Wuwu \& Co. in different moments of the narrative, and how does this relationship affect the reading experience?
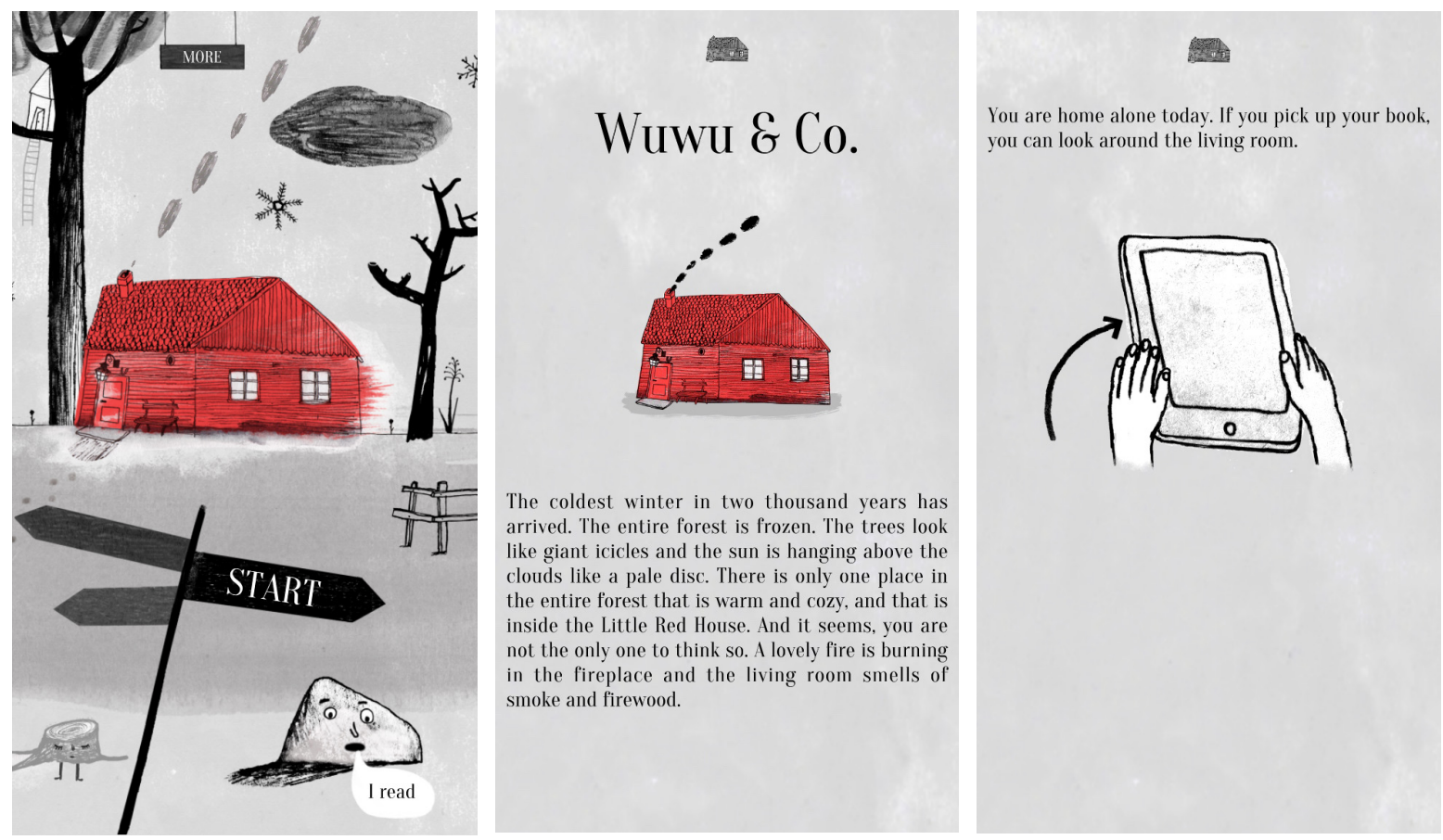

Illustration I. Illustrations from the app Wuwu \& Co. From the left: Front screen, first screen in narrative and first instruction mode screen. () Step In Books, 2015. 


\section{The App Wuwu \& Co. - A Magical Picturebook}

The app Wuwu \& Co. - A Magical Picturebook, marketed for ages six to eight, is available in Danish, English, German, French and Spanish. It has received good reviews and won several awards, amongst others, for best Nordic Children's Game at the 2015 Nordic Game Awards, and the Bologna Ragazzi Digital Award 2016 for best digital fiction. It can thus be regarded as an ambitious publication within this field in terms of interactive features and literary quality. Interestingly, even though the subtitle, "A Magical Picturebook", suggests that the app belongs to the literary realm, it is labelled and regarded as not only a literary production, but also as digital fiction and as game, depending on the reviewer and award. In the iTunes Store, it is also marketed as "Virtual Reality" for kids, which, in light of the subtitle, suggests a hybrid status as something more than a picturebook and something other than a game. This aligns with media scholar Ture Schwebs' description of digital fiction for children published as apps as hybrid literature. In this context, the idea of virtual reality seems extra suitable, considering Ryan's description of the reading experience. However, whereas Ryan's term refers to dimensions of a reading experience, the marketing label describes certain technical features offered by the app.

This hybrid status is also visually present in the app, which has parts that resemble book pages and parts that present the reader with interactive game-like activities in panorama scenes. In addition, the app offers an integrated soundscape and a performing voice, belonging to a performing narrator, that can be turned on or off. ${ }^{1}$ The narrative is fairly simple: As a reader, you are invited into a red house, where you have to open a door by using a hidden key, which allows five animated characters to enter (see ill. 1 and 2). You are then encouraged to help each character solve their individual problems, which leads to game-like episodes that take place in the woods surrounding the red house (see ill. 3). These episodes conclude the app.

The app has two narrative levels: an instruction level and a storytelling level. On the storytelling level the reader is addressed from within the narrative, by a narrator and characters that are seemingly unaware of the medium. On the instruction level the reader is addressed from within the tablet, and instructed on how to navigate by different physical actions (see ill. 1). The levels encourage different reading styles. Whereas the instruction level focuses on navigation and suggests what Rosenblatt has called efferent reading, i.e. reading for information, the storytelling level advocates what Rosenblatt 
calls aesthetic reading, i.e. reading for experiencing the narrative (The Reader, the Text, the Poem 24-25).

In my analysis, I look at how the reader is expected to participate through interactivity at four different moments of the app: the opening screen (outside the red house and on the threshold of fiction), the living room (inside the house), the entering of the characters (inside the house), and in the woods (surrounding the house). My focus is the reading experience and how this experience is affected by the interactive features as well as the possibilities for immersion.

\section{The Opening Screen: Two Different Aesthetic Experiences}

My first interactive decision as a reader takes place outside the narrative and concerns the choice between reading myself and being read to. This is a rather common feature in picturebook apps, but one that is rarely discussed in relation to the reading experience. The choice does not affect the narrative, as both choices take me to a screen that resembles a page in an illustrated book for children. If you choose to read yourself, the screen has no soundscape and is notably silent. The creation of atmosphere thus relies entirely on your own inner reading voice and the voice of the silent text. If you on the other hand choose to be read to, there is a performing narrator, reading the text aloud, and illustrative music playing in the background.

The interactive choice between the two different modes of reading yourself or being read to thus presents the reader with two entirely different modes of experience: one suggesting immersion through reading and looking, the other proposing immersion through looking and listening. Thus, the interactive choice also creates two different ways of participating, and at the same time, two entirely different aesthetic experiences. It is also worth taking into consideration how the choice of reading yourself requires a literate reader, whereas the narrated option also addresses itself to those who cannot read. As I continue, I will analyse the version where the story is read aloud, which is relevant when it comes to picturebook apps.

\section{First Moment: Entering the Living Room}

Once the narrator has read the introduction to the narrative, an arrow appears at the bottom right of the tablet, indicating that you should swipe to get to the next screen. There, an image of two hands holding an iPad appears, and the narrator suggests you lift the iPad and look around the living room (see ill. 1). Then a panorama screen 

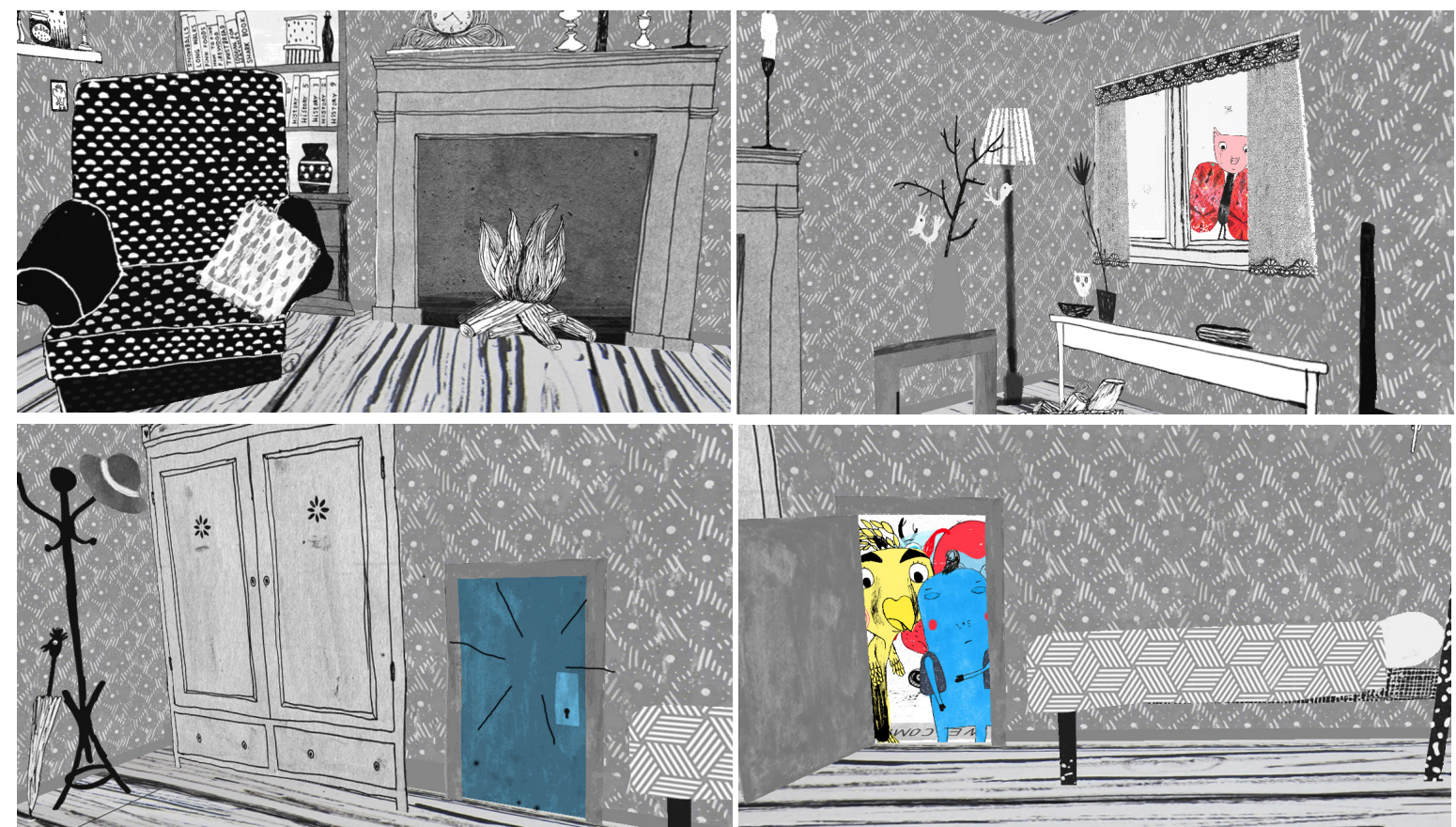

Illustration 2. Illustrations from the app Wuwu \& Co. Inside the living room (screen shots before and after opening the door). (C) Step In Books, 2015.

portraying the inside of a living room appears, and the perspective changes from third-person to first-person (see ill. 2). This way, you are literally transported from outside the narrative and to the inside, invited into a world (cf. Ryan), and offered immersion in the spatio-temporal sense.

In the living room, no explicit instructions are given at first, and to get an overview of the entire room, you must stand up and spin around. This act alters the user's role from being that of merely a reader, to becoming a physically participating actor within the frames of the narrative. This particular interactive feature invites the reader to examine the living room in a playful manner, engaging the entire body, adding the pleasure of physical play, especially that of spinning, to the activity of getting familiar with the living room in the red house. One can of course limit the spinning around to a required minimum, but there is also the possibility to immerse oneself thoroughly in the world created by the app by spinning continuously. In this way, the room offered by the app is also expanded, as it includes both the living room on the screen and the actual surroundings of the current reader. 
The act of spinning and looking around is however interrupted within a few seconds by explicit calls for another kind of interactive participation, proposed by different characters shouting and knocking on the door to the panorama living room. They want to get in, and for that to happen, they explain, they need you to find a key and open the door (see ill. 2). Once the door is opened, five characters stumble in and place themselves around the living room. The interactivity in this part of the narrative, i.e. the opening of the door, can be described as internal-ontological, meaning conducted by the reader in the role of a member of the storyworld and with abilities to perform actions that bring lasting changes to the narrative. These are qualities that one would think adds to the experience of the narrative, and in other circumstances perhaps would be regarded as a sign of successful or so-called real participation. When discussed in relation to immersion as well as the reading experience, the situation alters.

Firstly, the task of opening the door is proposed almost instantly after entering the living room. Thus, there is no time for the reader to explore the room properly before being interrupted. How we experience the passing of time in a narrative is, of course, individual. Even so, here it seems that a scene that could have created suspense (what will happen here, what will happen next?), is partly obstructed by the immediate knock on the door. Regarding a picturebook app as an event means taking into consideration the dramaturgical structuring of the reading experience. Here, the knocking seems premature, at least for a first time-reader, be it a child or an adult. Secondly, to open the door, one only has to follow a pre-set pattern of tapping: The door, the key and the door again. The task is easily solved for a reader familiar with following simple and explicit instructions. In other words, the task-solving proposes no real challenge, even though the prescribed actions affect the narrative. What happens here can thus be described as the interactive features of one part of the narrative, i.e. opening the door, interfering with the immersive experience devised by the other, i.e. the living room panorama. Put differently, the sense of space and atmosphere is undermined and the panorama experience is to some degree destroyed by what can be described as an obtrusion of spatio-temporal immersion.

\section{Second Moment: Enter the Characters}

Once the characters have entered, they hang around the living room, looking directly at the reader without saying a word. This encourages the reader to explore the screen by touching different objects, 
first and foremost the different characters. When tapped, they address you directly, and respond by in different ways suggesting you should put the iPad down and listen to their story, as each of them have a problem that they need help solving. Thit Maya, for instance, says: "My little friends are so hungry. Look down to find out why." And Everett goes: "Hurry up and read my story. Look down, you have to be quick". Once again, the reader is conceptualised as an active participant in the narrative, this time also with the explicit plea for help. This gives the reader the opportunity to take part in what can be described as internal-ontological interactivity. The plea for help, combined with the characters' peculiar animal-like looks, distinct personalities and soft and cautious voices, create an empathic atmosphere. This can be linked to the creation of Ryan's category emotional immersion, as well as the already established spatiotemporal world.

The problem here is that even though this moment thus signalises a certain type of interactivity, as suggested above, the lines of the characters also indicate a different situation. As they ask the reader for help and at the same time ask the reader to look down to hear their story, the characters incorporate what I have earlier referred to as the instruction level and the storytelling level simultaneously. The command "Look down" is not related to the narrative, but is in fact an instruction relating to the tablet (i.e. the medium), meaning "put the iPad down". As a consequence, the characters' need for help suddenly appears in another light, as they send a double message: They are at the same time narrated characters and instructors, as they know how the reader needs to act to solve their problems. This doubleness raises the question of whether the reader's participation is of any real importance, as the characters also communicate a different message than a plea for help. The message can be described as "follow our lead", which creates a new hierarchy, as the reader now seems to be the one who knows the least. The interactivity proposed here, which seems to encourage emotional immersion by means of empathy and identification (the cry for help, the pleading eyes), is thus opposed by the narrating characters themselves, who create a narrative distance by means of their roles as instructors as well as acting characters.

\section{Third Moment: In the Woods}

When you eventually put the iPad down as told, you arrive once again at the book-like screen, where the narrator reads aloud a short story about the chosen character. As there are five characters, 


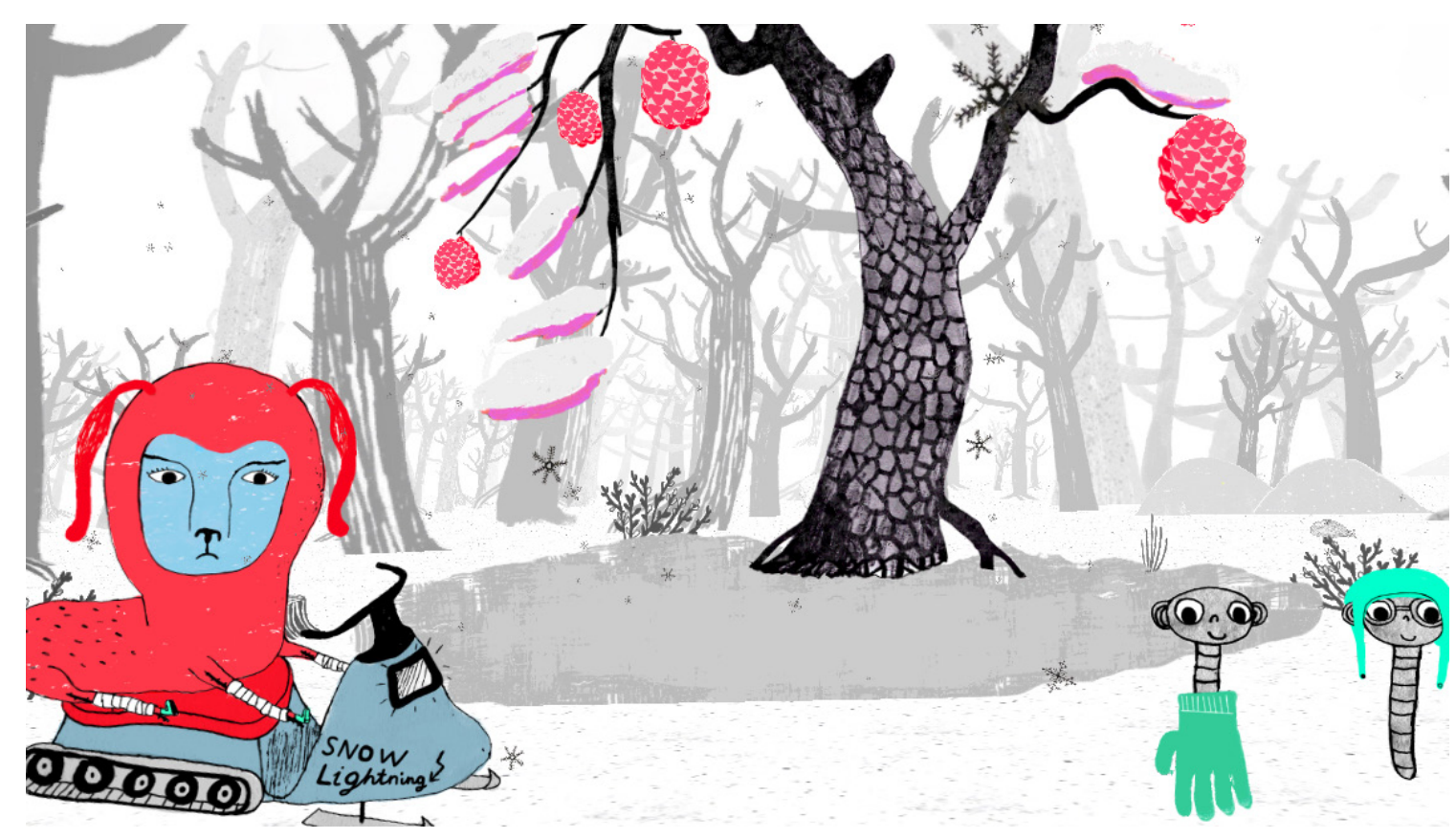

Illustration 3.Thit Maya needs you to shake the pine cones down from the tree. (C) Step In Books, 2015.

there are five different stories to choose between. The stories are similar, and relate the trouble this particular character is in and the problems they need help solving. For each story, the narrator presents the reader with a background story for the specific character. At the end of each story, you are addressed in second-person and encouraged to help in a certain way. For instance, in the case of Thit Maya, we learn that she and her friends love pine cones, but when Thit Maya breaks all of her four legs falling on the ice and no longer is able to shake down pine cones from the pine trees, they are all in danger of starving. Therefore, Thit Maya needs you to help her get pine cones down from a tree, which is relayed by the narrator in a direct address to the reader: "Can you help Thit Maya and her friends shake the pine tree?" (see ill. 3). Then, he continues by giving instructions: "Remember what she said: First the snow has to be shaken off, and then the pinecones have to be shaken to the ground."

When lifting the iPad at the end of each of these five different stories, the reader can enter a new panorama, this time in a forest surrounding the red house (which is visible through the trees). Inter- 
estingly, unlike in the living room, here you are free to enjoy the panorama of the forest as long as you like, as nothing happens by itself. Therefore, you are forced to look around by spinning and further, to explore your opportunities by tapping on the screen. For instance, tapping Thit Maya results in her saying: "Well, I can't shake the tree. Can you?", implying once again that there are certain actions the reader should perform. In this particular story, what is needed is for the reader to physically shake the tablet. Even though there at this point in time are several gaming devices designed for active physical use, a tablet has a breakable screen and is therefore normally considered to be an object one needs to handle with a certain care. Therefore, to shake it hard and fast can be experienced as both subversive and intriguing at the same time. In this particular case, it is also a meaningful act within the narrative frame, as the shaking is explicitly required and therefore done for a specific reason. The interactive experience at this particular moment of the narrative can thus be described as interactive and immersive at the same time. Here too, the interactivity is internal-ontological.

However, the whole sequence is over in less than thirty seconds. After shaking the tablet for no more than five seconds (at the most), all pine cones have fallen to the ground, and Thit Maya and her friends cheer and applaud the effort, before they welcome you back another time. If you want to continue reading the app, returning to the house is the only possible solution. In this way, the reader's involvement in the narrative by means of interactivity and immersion is very short-lasting, especially taking into consideration how much time and effort the narrator has invested in preparing the reader for the final task of shaking the pine tree. The same thing happens in all five stories: The tasks are immersive, and engage the body and the mind in various playful activities (shouting, tapping, filming, shaking), but the tasks are very short-lasting. How this is experienced may of course vary with age and experience. In my case, it seemed as if the tasks were solved at the very moment I became immersed and was ready to invest myself deeper in the narrative by means of the interactive features. This happened even though the interactivity could be described as internal-ontological. It was of little consolation that I could enter the story and solve the task once more if I wanted, as the activities remained the same: short-lasting, and, moreover, offered little challenge once solved the first time. The app ends when the reader has solved the problems of all five characters. 


\section{The App as an Event: Immersion and Interactivity}

Analysing a picturebook app as an event means expanding the analytical object from consisting of merely the picturebook app itself to including the reading experience as well. In this article I have focused on the interactive features, discussing how they affect the reading experience when seen in relation to Ryan's proposition of interactivity and immersion as the two central elements in the phenomenology of reading.

The chosen analytical perspective makes it possible to discuss the overall relations between interactivity and immersion from the readers point of view. In the case of Wuwu $\&$ Co., I argue that there seems to be a discrepancy between the interactive and immersive experiences offered. The discrepancy is caused by the interactive features that at different moments interrupt either temporal, spatial or emotional immersion.

As described above, one disruption is related to the relation between the instruction mode and the storytelling mode, both from within the iPad and from within the narrative. One could perhaps argue that interactivity guidance is unavoidable, but the effect is still that immersion is interrupted. Another disruption is related to temporal immersion, as described in the living room scene, where the instant introduction of the interactive features seem to interrupt the immersive experience suggested by the panorama. The last disruption relates to the game-like elements related to the five characters. The five different tasks present the reader with the opportunity to immerse herself in the narrative both spatially, temporally and emotionally, but they all last a very short time. In that way, the interactive features could be regarded as interrupting immersion rather than creating it, paradoxically for the sake of the interactive progression of the narrative. This happens even though the interactivity can be described as internal-ontological, and also as related to the narrative.

As a consequence, I will argue that a discussion of the significance of interactivity in digital narratives for children cannot be limited to including the formal, intra-fictional relationship between the narrative and the interactive features. Rather, such a discussion must also include the reader and the reading experience. To regard an app as an event, following the theoretical and analytical concept of Sauter's theatrical event, allows for such a perspective and gives the children's literature researcher the opportunity to include the experience of interactivity in an analysis of a picturebook app. What furthermore becomes evident by means of this analytical approach 
is that the significance of interactivity in such publications cannot be discussed in general terms, but must always be discussed in relation to the individual artistic project in which it operates. There is, however, reason to argue that certain forms of interactivity invite certain responses from an audience (Nagel and Hovik), a notion that also would apply to the reader of digital narratives. This means that an analysis of interactivity in digital narratives on tablets will have to include both a discussion of how the interactive features are intended to work, and further, an evaluation of the actual effect of the interactive feature, when realised by a reader as a live event.

\section{Summing Up}

To analyse an app as an event, focusing on reading as a realisation of the narrative and on the reading experience, sheds light on different aspects of the interactive features than a work-oriented analysis would. Instead of valuing interactivity as either true or false, or as meaningful or meaningless, interactivity is valued in relation to the narrative and the creation of a temporal, spatial and emotional immersion. This alters the question from what interactivity is to what interactivity does: How do the interactive features work to create what kind of interactive reading experience? It can also be regarded as changing the focus from the work of art to the reader, which could open for interesting questions concerning both the significance of the child reader's experiences and the relationship between intended and experienced interactivity.

Biographical information: Lisa Nagel is a Ph.D. scholar at the Norwegian Institute for Children's books and the University of Oslo, where she works on an interdisciplinary thesis on performing arts for children and children's literature as events, titled Kunst for barn som hendelser: En kritisk diskusjon av analytiske perspektiver i kunst for barn, med eksempler fra scenekunst, bildebøker og bildebokapper (2018). Her background is drama pedagogy and theatre and performance studies. Recent publications include "The SceSam-project: Interactive Dramaturgies in Performing Arts for Children" (Lisa Nagel and Lise Hovik 2016), Deltakelse og interaktivitet i scenekunst for barn (Lise Hovik and Lisa Nagel 2017) and "Den likeverdige tilskueren i scenekunst for barn" (Lisa Nagel 2017). 


\section{Works Cited}

Aylett, Ruth, and Sandy Louchart. "Narrative Theory and Emergent Interactive Narrative." International Journal of Continuing Engineering Education and Life Long Learning, vol 14, no. 6, 2004, pp. 506-518, https:/ / doi.org/10.1504/IJCEELL.2004.006017. Accessed 8 July 2017.

Al-Yaqout, Ghada, and Maria Nikolajeva. "Re-conceptualising Picturebook Theory in the Digital Age." Nordic Journal of ChildLit Aesthetics, vol 6, no. 1, 2015, n.pag., https://doi.org/10.3402/blft. v6.26971. Accessed 28 May 2016.

Gadamer, Hans-Georg. Truth and Method. 1975. Translation revised by Joel Weinsheimer and Donald G. Marshall, $2^{\text {nd }}$ rev.ed, Continuum, 2004.

Have, Iben and Birigitte Stougaard Pedersen. Digital Audiobooks: New Media, Users, and Experiences. Routledge, 2015.

Hayles, N. Katherine. "The time of digital poetry: From object to event." New Media Poetics: Contexts, Technotexts, and Theories, edited by Adalaide Morris and Thomas Swiss. MIT Press, 2006, pp. 181-209.

Helle, Merete Pryds and Kamila Slocinska. Wuwu \& Co. - A Magical Picturebook. Step In Books, 2014.

Nagel, Lisa and Lise Hovik. "The SceSam-project: Interactive Dramaturgies in Performing Arts for Children." Youth Theatre Journal, vol. 30, no. 2, 2016, pp. 149-170, http:/ / dx.doi.org/10.1080/08929092.20 16.1225611. Accessed 8 July 2017.

Pimentel, Ken and Kevin Teixeira. Virtual Reality: Through the New Looking Glass. Intel/Windcrest McGraw Hill, 1993.

Rosenblatt, Louise M. “The Poem as Event." College English, vol. 26, no. 2, 1964, pp. 123-128.

- - - The Reader, the Text, the Poem: The Transactional Theory of the Literary Work. Southern Illinois University Press, 1978.

Ryan, Marie-Laure. Narrative as Virtual Reality 2: Revisiting Immersion and Interactivity in Literature and Electronic Media. Johns Hopkins University Press, 2015.

Sauter, Willmar. The Theatrical Event: Dynamics of Performance and Perception. University of Iowa Press, 2000. 
Schwebs, Ture. "Affordances of an App: A Reading of The Fantastic Flying Books of Mr. Morris Lessmore." Nordic Journal of ChildLit Aesthetics, vol. 5, no. 1, 2014, n.pag., https://doi.org/10.3402/blft. v5.24169. Accessed 28 May 2016.

Stichnothe, Hadassah. "Engineering stories? A Narratological Approach to Children's Book Apps." Nordic Journal of ChildLit Aesthetics, vol 5, no. 1, 2014, n.pag., https:// doi.org/10.3402/blft.v5.23602. Accessed 28 May 2016.

Turrión, Celia. "Multimedia Book Apps in a Contemporary Culture: Commerce and Innovation, Continuity and Rupture." Nordic Journal of ChildLit Aesthetics, vol. 5, no. 1, 2014, n.pag., https://doi. org/10.3402/blft.v5.24426. Accessed 28 May 2016.

\section{Notes}

1 The performing voice and the performing narrator are terms used by audio book scholars Iben Have and Birgitte Stougaard Pedersen to distinguish between the narrator on the textual level and the audio narrator in audio books (79). I find the terms relevant in a discussion of picturebook apps as well. 